OPEN ACCESS

Authors' contribution:

A) conception and design of the study

B) acquisition of data

C) analysis and interpretation of data

D) manuscript preparation

E) obtaining funding

\title{
Motivation Psychological Characteristics of Canoe-Kayak Sprint Elite Youth Athletes
}

\author{
Evangelos Bebetsos A,C, Emmanuel Aggelakis B,C, \\ George Bebetsos ${ }^{\mathrm{D}}$, Dimitrios Gargalianos ${ }^{\mathrm{D}}$ \\ Democritus University of Thrace, Komotini, Greece
}

ABSTRACT

The objective of the current study was the investigation of anxiety and satisfaction levels among Elite Greek Youth athletes of Canoe-Kayak Sprint. Additionally, whether elements such as gender, age, athletic experience, and weekly practice-time, differentiated the sample. 122 athletes, (61 males and 61 females) between the ages of 15-17 yrs. old, who competed in the Hellenic Federation's Canoe-Kayak Sprint National Championships. Study participants were invited to complete two questionnaires: a) the Greek version of "CSAI-2” (Stavrou, Zervas, Kakkos, \& Psichoundaki, 1998), and b) the Greek version of the "Athlete Satisfaction" scale (Bebetsos \& Theodorakis, 2003). Results of the conducted study revealed that the sample differentiated: a) on somatic, and cognitive anxiety, according to their athletic experience, and b) on somatic, and cognitive anxiety, self-confidence, leadership, and personal outcome, according to their weekly practice-time. Finally, no sex differences were found in any questionnaire variable. In conclusion, the survey results highlighted the importance of the psychological factors tested on Canoe-Kayak Sprint athletes' performance. Knowing and understanding athletes' psychological state, can help them out (the athletes) in identifying aspects such as stress and satisfaction that directly affect their racing performance.

KEYWORDS cognitive anxiety, somatic anxiety, self-confidence, leadership, personal outcome

\section{Introduction}

Scientists (Spielberger, 1989; Mauss \& Robinson, 2009) documented that anxiety does not exist as a single cognitive-emotional and physiological state, and suggested to differentiate it as:

a) state anxiety, where it was reported, in subjective, as conscious perceptions of anxiety and tension, accompanied or associated with activation or stimulation of the autonomic nervous system, and

b) anxiety as a personality trait or trait anxiety, where reference was made to an acquired behavioral predisposition, where an individual perceives a large number of objectively non-threatening situations as threatening and respond to them with occasional anxiety reactions disproportionate to the size of the objective risk. Predisposing anxiety suggested relative permanent differences in an individual's anxiety tendency, which was a characteristic of his personality. Existing individual differences were the ones that determined what stimuli were rated as threatening. 
Anxiety was defined as a complex psychobiological process, accompanied by unpleasant feelings and negative thoughts. In this psychobiological process three stages were distinguished:

a) a stressful stimulus,

b) an interpretation, and

c) an emotional reaction of anxiety.

The individual was able to reassess the stressful situations caused by stress, resulting in a cognitive reassessment. If it was not possible to act in one way or the other, the individual actuated mental defense mechanisms, which resulted in anxiety reduction (Spielberger, 1989).

In recent years, sports psychologists (Ford et al., 2017; Binboga et al., 2012; Bebetsos, 2015; Bebetsos \& Goulimaris, 2015) have used modifications to the definition formulated by McGarthy (1970). According to the researcher, anxiety is experienced when environmental demands, as perceived by the individual, exceed his/her ability to cope with them. His model included 4 stages:

a) environmental stimulus requiring reaction by individuals,

b) personal perception of the environmental stimulus,

c) perception of threat and response, and

d) behavior, effort or avoidance.

According to Hagan and his colleagues (2017b), in sports activities, many athletes failed to perform according to their potential, due to anxiety. The weaknesses presented in the theoretical interpretations of the relationship between anxiety and athletic performance has led to the finding that it is methodologically more appropriate to distinguish anxiety: a) as a relatively stable personality trait, and b) as a temporary and instantaneous state. Nowadays, stress is characterized as a reaction to a variety of external or internal factors that threaten to alter the homeostasis of the organism (Chovatiya \& Medzhitov, 2014).

Morris et al. (1981), and Martens, Vealey, and Burton (1990), supporting the distinction of anxiety components, note the existence of two types of anxiety such as cognitive and somatic anxiety. Cognitive anxiety is the mental (mental) dimension of anxiety and is caused by the negative expectations of the individual for performance and success, or by negative self-evaluation. Both situations cause concern and damage mental images. When athletes worry, they are concerned with assessing themselves and they are thinking of a possible failure. As a result, they cannot direct their attention to their effort and generally to the demands of the sport activity.

High levels of cognitive and physical anxiety are unpleasant to the individual and adversely affect performance. Physical state anxiety (e.g. muscle tension) affects less performance than cognitive anxiety (e.g. anxiety), except when body stress is at such a high level that the caused internal conditions (e.g. heart rate increase) do not allow attention to be drawn or where the demands of effort (e.g. race duration and complexity) are high (Salmon, 2001).

Another important factor psychological factor affects sport performance is the level of athlete's satisfaction, which has been defined as a "positive affective state resulting from a complex evaluation of the structures, processes, and outcomes associated with the athletic experience" (Chelladurai \& Riemer, 1997, p. 133). Athletes' satisfaction is a multidimensional concept and it is influenced by many factors such as leadership, personal performance, team participation, facilities, team performance, and performance of other teams. "Leadership" refers to how satisfied are athletes from their coach's behavior, while "Personal Outcome" refers to how satisfied are athletes from their own performance (Riemer \& Chelladurai, 1998; Moen, 2014; Ignacio, Montecalbo-Ignacio, \& Cardenas, 2017).

The meaning of the term leadership is: "the process of influencing the activities of an organized group in its efforts to achieve a particular goal" (Barrow, 1977, p. 232). The widespread belief, especially among coaches, that there is a strong relationship between athletes' satisfaction and their efficiency, shows even further the importance of investigating this specific topic. Additionally, analyses revealed that sex, weekly practice-time 
and athletic experience were diversified aspects of satisfaction (Papadopoulou, Theodorakis, Tsigilis, \& Tsalis, 2006; Bebetsos, Filippou, \& Bebetsos, 2017).

\section{Aim of the study}

The purpose of this research was the investigation of possible relation among anxiety and satisfaction levels of Elite Greek Youth Canoe-Kayak Sprint athletes. More specifically, the research investigated differences on:
a) sex;
b) national category; and
c) weekly practice-time.

\section{Uniqueness of the study}

No equivalent research work in the sport of Canoe-Kayak Sprint, in both Greek and International literature was found.

\section{Methods}

\section{Sample}

The sample consisted of 122 Elite athletes, (61 males and 61 females) between the ages of 15-17 yrs. old $(M .=15.97$, S.D. $=.85)$. Additionally, they were divided according to their athletic experience, and weeklypractice time (Table 1). Athletes completed the questionnaire after their participation in the Greek Men's and Women's National Championship Tournament. Participation was voluntary. All participants were assured for confidentiality and that they could stop whenever they wanted.

Table 1. Descriptive characteristics of the sample

\begin{tabular}{lcc}
\hline Variables & $\mathbf{N}$ & $\mathbf{\%}$ \\
\hline Age groups & & \\
15 & 46 & 37.7 \\
16 & 34 & 27.9 \\
17 & 42 & 34.4 \\
Sex & & \\
$\quad$ Male & 61 & 50 \\
Female & 61 & 50 \\
Athletic Experience & & \\
$0-2$ yrs & 34 & 27.9 \\
$3-4$ yrs & 40 & 32.8 \\
$\geq 5$ yrs & 48 & 39.3 \\
Weekly-practice time & & \\
$0-4$ & 34 & 28.1 \\
5-7 & 48 & 39.7 \\
$\geq 8$ & 39 & 32.2 \\
National category & & \\
Boys & 33 & 27 \\
Junio boys & 41 & 33.6 \\
Girls & 28 & 23 \\
Junior girls & 20 & 16.4 \\
\hline
\end{tabular}

Source: own study. 


\section{Instrumentation}

1. Competitive State Anxiety

The Greek version (Stavrou, Zervas, Kakkos, \& Psichountaki, 1998) of the "CSAI-2" (Martens, Burton, Vealey, Bump, \& Smith, 1990) was used which includes three subscales:

a) Cognitive Anxiety (e.g. "I was worried if I would achieve my goal"),

b) Somatic Anxiety (e.g. "I felt tension in my body"), and

c) Self-confidence (e.g. "I was very sure of myself"), with five items in each scale. On a 4-point Likert scale $(1=$ not at all, $4=$ very much so $)$ respondents rated the intensity of their anxiety and selfconfidence competition experiences.

2) Athlete Satisfaction

The Greek version (Bebetsos \& Theodorakis, 2003) of the Scale of "Athlete Satisfaction" (Chelladurai, Imamura, Yamaguchi, Oimnuma, \& Miyauchi, 1988; Chelladurai \& Riemer, 1997). The questionnaire consists of 10 items measuring athletes' satisfaction in two dimensions:

a) Leadership (7 items, e.g., "The leadership provided by my coach"),

b) Personal Outcome (3 items, e.g., "The way I was performing"). Responders were instructed to indicate the extent of their satisfaction in each item on a 7-point Likert-type scale ranging from 1 (extremely dissatisfied) to 7 (extremely satisfied).

\section{Statistical analysis}

To investigate differences between sexes, weekly practice time, and athletic experience for each factor of the questionnaire, univariate analyses were conducted. The post hoc multiple comparisons Scheffe test was used to define the statistically significant differences between groups.

\section{Results}

\section{Psychometric Characteristics}

The internal consistency for the variables of both questionnaires, were:

a) Cognitive Anxiety .80,

b) Somatic Anxiety .78,

c) Self-confidence .89,

d) Leadership .86, and

e) Personal Outcome .89 .

\section{Sex and Athletic Experience}

Univariate analyses were conducted to check-out any gender and/or athletic experience related differences. The analyses revealed the following statistical significant differences:

a) For the variable of "Somatic Anxiety" a significant main effect for athletic experience was shown: $\mathrm{F}_{2,116}=7.198, \mathrm{p}<.001$. The post hoc Scheffe test showed that the differences were detected between Junior Boys $(\boldsymbol{M = 2 . 6 0}, \boldsymbol{S D}=\mathbf{. 7 7})$ with Male Adolescents $(M=2.03, S D=.69)$, and Junior Girls $(\boldsymbol{M = 2 . 4 1}$, $S D=.75)$ with Female Adolescents $(M=1.83, S D=.76)$.

b) For the variable of "Cognitive Anxiety" a significant main effect for athletic experience was shown: a significant main effect for athletic experience was shown: $F_{2,115}=7.62, p<.001$. The post hoc Scheffe test showed that the differences were detected only between the least experienced athletes ( $1^{\text {st }}$ group) $(\boldsymbol{M}=\mathbf{2 . 8 0}, \boldsymbol{S D}=\mathbf{. 8 3})$, and the most experienced ( $3^{\text {rd }}$ group) $(M=2.29, S D=.80)$. 


\section{Weekly Practice and Athletic Experience}

Univariate analyses were conducted to check-out any weekly practice-time and/or athletic experience related differences. The analyses revealed the following statistical significant differences:

a) For the variable of "Somatic Anxiety" a significant main effect for athletic experience was shown: $\mathrm{F}_{6,109}=1.28, \mathrm{p}<.001$. The post hoc Scheffe test showed that the differences were detected between the least experienced athletes ( $1^{\text {st }}$ group $)(M=2.68, S D=.73)$ with both the intermediate experienced $\left(2^{\text {nd }}\right.$ group) ( $M=2.16, S D=.75)$, and the most experienced ( $3^{\text {rd }}$ group) $(M=1.98, S D=.70)$.

b) For the variable of "Cognitive Anxiety" a significant main effect for athletic experience was shown: $\mathrm{F}_{4,111}=.669, \mathrm{p}<.001$. The post hoc Scheffe test showed that the differences were detected between the least experienced athletes ( $1^{\text {st }}$ group) $(\boldsymbol{M = 2 . 7 4}, S D=.84)$ with both the intermediate experienced athletes ( $2^{\text {nd }}$ group) $(M=2.51, S D=.80)$, and the most experienced ( $3^{\text {rd }}$ group) $(M=2.09, S D=.62)$.

c) For the variable of "Self-confidence" a significant main effect for athletic experience was shown: a significant main effect for athletic experience was shown: $\mathrm{F}_{4,111}=3.85, \mathrm{p}<.001$ The post hoc Scheffe test showed that the differences were detected between the most experienced athletes ( $3^{\text {rd }}$ group) $(\boldsymbol{M}=\mathbf{3 . 0 6}$, $S D=.92)$ with both the intermediate experienced ( $2^{\text {nd }}$ group) $(M=2.73, S D=.72)$, and the least experienced ( $1^{\text {st }}$ group $)(M=1.77, S D=.67)$.

d) For the variable of "Personal Outcome" a significant main effect for athletic experience was shown: a significant main effect for athletic experience was shown: $\mathrm{F}_{4,112}=1.54, \mathrm{p}<.001$ The post hoc Scheffe test showed that the differences were detected between the most experienced athletes ( $3^{\text {rd }}$ group $)(\boldsymbol{M}=\mathbf{5 . 6 6}$, $S D=.91)$ with both the intermediate experienced ( $2^{\text {nd }}$ group) $(M=5.03, S D=.93)$, and the least experienced ( $1^{\text {st }}$ group) $(M=4.76, S D=1.29)$.

e) For the variable of "Leadership" a significant main effect for athletic experience was shown: a significant main effect for athletic experience was shown: $\mathrm{F}_{6,109}=2.33, \mathrm{p}<.001$ The post hoc Scheffe test showed that the differences were detected between the most experienced athletes ( $3^{\text {rd }}$ group) $(\boldsymbol{M}=\mathbf{6 . 1 4}$, $S D=.74)$ with both the intermediate experienced ( $2^{\text {nd }}$ group) $(M=4.78, S D=.1 .35)$, and the least experienced ( $1^{\text {st }}$ group) $(M=4.55, S D=1.01)$.

\section{Discussion}

The main purpose of this study was to investigate the levels of anxiety and satisfaction among Elite Greek Youth athletes of Canoe-Kayak Sprint. To the best of the researchers' knowledge, no similar studies have been conducted on the specific topic - in sport psychology both internationally, and in Greece. Therefore, discussion and conclusions from the present study reflect a first attempt to interpret the relation of these psychological aspects as regards to competition experience, and weekly practice-time.

To begin with, researches identified and supported previews studies' results were older, and the more experienced athletes achieved higher scores in the variables of "Self-confidence", "Personal Outcome", and "Leadership", than the younger and less experienced ones. Additionally, more practice is likely to develop and strengthen performance (Givens, 2008; Papadopoulou, Theodorakis, Tsigilis, \& Tsalis, 2006; Merkel, 2013; Bebetsos, Filippou, \& Bebetsos, 2017). Consequently, better personal outcomes and satisfaction with high expectations on performance, become more realistic after years of experience. As Carron and Spink (1993) proposed, athletes with greater athletic experience may be more confident and have higher prestige, and as a result, their satisfaction is high. Regarding sex, there were no statistically significant differences between youth athletes in the examined questionnaire of "Athlete Satisfaction". As earlier results pointed-out (Brisimis, Bebetsos, \& Krommidas, 2018), this finding shows that youth female athletes do not perceive differently the concepts of satisfaction than youth males, and have similar demands from their coach both in technical and behavioral levels. 
On the other hand, younger athletes from both sexes illustrated high levels of somatic and cognitive anxiety than the older and more experienced ones. Similarly, as past researchers mentioned that more sport-experienced athletes manage better with indifferent situations, especially on individual sports (Bebetsos \& Antoniou, 2012; Bebetsos, 2015). Moreover, Gould and Maynard (2009) pointed-out that elite sports are characterized mainly by situational contexts, where stress is induced. Overall, elite athletes are individuals who take time to "correct" decision(s) for better possible outcome(s) (Calmeiro, Tenenbaum, \& Eccles, 2014).

Finally, results did not indicate any sex differences. Researchers supported previous findings (Bebetsos \& Antoniou, 2012; Bebetsos \& Goulimaris, 2015; Bebetsos, 2015). It should be noted that mainly in Greece both men and women Canoe-Kayak Sprint athletes, practice on the same courts, with the same coaches. Moreover, Canoe-Kayak is an adaptive sport, generally independent from sex, so researchers assumed that this might be the reason. Of course, it also should be noted that assessing sex differences among elite athletes is relatively minimal (Woodman \& Hardy, 2003), where cultural differences and cultural perspective(s) were cited as potential reasons for the variance of their sample (Basabe et al., 2000; Mesquita \& Markus, 2004; Hagan et al., 2017a).

A limitation of the current investigation could be considered the self-report methodology that was employed.

\section{Conclusion}

In conclusion, the results of the research can help athletes understand and interpret the attributes that affect performance in the sport of Canoe-Kayak Sprint. The aim is to maximize team performance through the cultivation of the factors that strengthen it and the restraint of those who prevent it. The results of the research attempt to clarify the importance of these factors and enable athletes to interpret them to their advantage. Finally, these results can provide a basis for further scientific research into this highly comparative sport.

\section{REFERENCES}

Barrow, J.C. (1977). The variables of leadership: A review and conceptual framework. Academy of Management Review, 2, 231-251.

Basabe, N., et al. (2000). Sociocultural factors predicting subjective experience of emotion: a collective level analysis. Psicothema, 12(Suppl.), 55-69.

Bebetsos, E. (2015). Psychological skills of elite archery athletes. Journal of Human Sport \& Exercise, 10(2), 623-628.

Bebetsos, E., \& Antoniou, P. (2012). Competitive state anxiety and gender differences among youth Greek badminton players. Journal of Physical Education and Sport, 12(1), 107-110.

Bebetsos, E., Filippou, F., \& Bebetsos, G. (2017). Athletes' criticism of coaching behavior: Differences among gender, and type of sport. Polish Psychological Bulletin, 48(1), 66-71.

Bebetsos, E., \& Goulimaris, D. (2015). Examination of "Pre-competition" anxiety levels, of mid-distance runners: A quantitative approach. Polish Psychological Bulletin, 46(3), 498-502.

Bebetsos, E., \& Theodorakis, N. (2003). Athletes' satisfaction among team handball players in Greece. Perceptual and Motor Skills, 97(3), 1203-1208.

Binboga, E., Guven, S., Catikkas, F., Bayazit, O., \& Tok, S. (2012). Psychophysiological responses to competition and the big five personality traits. Journal of Human Kinetics, 33, 187-194.

Brisimis, E., Bebetsos, E., \& Krommidas, Ch. (2018). Does group cohesion predict team sport athletes' satisfaction? Hellenic Journal of Psychology, 15, 108-124.

Calmeiro, L., Tenenbaum, G., \& Eccles, D.W. (2014). Managing pressure: patterns of appraisals and coping strategies of non-elite and elite athletes during competition. Journal of Sport Sciences, 32(19), 1813-1820.

Carron, A.V., \& Spink, K.S. (1993). Team building in an exercise setting. The Sport Psychologist, 7, 8-18.

Chelladurai, P., \& Riemer, H. (1997). A classification of facets of athlete satisfaction. Journal of Sport Management, 11, 133-159.

Chelladurai, P., Imamura, H., Yamaguchi, Y., Oimnuma, Y., \& Miyauchi, T. (1988). Sport leadership in a cross-national setting: The case of Japanese and Canadian University athletes. Journal of Sport \& Exercise Psychology, 10, 374-389. 
Chovatiya, R., \& Medzhitov, R. (2014). Stress, Inflammation, and Defense of Homeostasis. Molecular Cell, 54(2), 281288.

Ford, J.L., Ildefonso, K., Jones, M.L., \& Arvinen-Barrow, M. (2017). Sport-related anxiety: current insights. Open Access Journal of Sports Medicine, 8, 205-212.

Givens, R.J. (2008). Transformational Leadership: The Impact on Organizational and Personal Outcomes. Emerging Leadership Journeys, 1(1), 4-24.

Gould, D., \& Maynard, I. (2009). Psychological preparation for the Olympic games. Journal of Sports Sciences, 27, 1393 1408.

Hagan, J.E., Pollmann, D., \& Schack, T. (2017a). Interaction between gender and skill on competitive state anxiety using the time-to-event paradigm: what roles do intensity, direction, and frequency dimensions play? Frontiers in Psychology, 8. DOI: 10.3389/fpsyg.2017.00692.

Hagan, J.E., Pollmann, D., \& Schack, T. (2017b). Elite Athletes' In-event Competitive Anxiety Responses and Psychological Skills Usage under Differing Conditions. Frontiers in Psychology, 8. DOI: 10.3389/fpsyg.2017.02280.

Ignacio, R.A., Montecalbo-Ignacio, R.C., Cardenas, R.C. (2017). The Relationship between Perceived Coach Leadership Behaviors and Athletes Satisfaction. International Journal of Sports Science, 7(5), 196-202.

McGrathy, J. (1970). Social and psychological factors on stress. New York: Holt, Rinehart \& Winston.

Martens, R., Vealey, R. S., \& Burton, D. (1990). Competitive anxiety in sport. Champaign, IL: Human Kinetics.

Martens, R., Burton, D., Vealey, R.S., Bump, L.A., \& Smith, D.E. (1990). Development and validation of the competitive state anxiety inventory-2 (CSAI-2). In R. Martens, R. S. Vealey, \& D. Burton (Eds.), Competitive Anxiety in Sport (pp. 117-173). Champaign, IL: Human Kinetics.

Mauss, I.B., \& Robinson, M.D. (2009). Measures of emotion: A review. Cognition \& Emotion, 23(2), 209-237.

Merkel, D.L. (2013). Youth sport: positive and negative impact on young athletes. Open Access Journal of Sports Medicine, 4, 151-160.

Mesquita, B., \& Markus, H.R. (2004). Culture and emotion: models of agency as sources of cultural variation in emotion. In N. H. Frijda, A.S.R. Manstead, \& A. Fisher (Eds.), Feelings and Emotions: The Amsterdam Symposium. Cambridge University Press. DOI: 10.1017/CBO9780511806582.020.

Moen, F. (2014). The Coach-Athlete Relationship and Expectations. International Journal of Humanities and Social Science, 4(11), 29-40.

Morris, L.W., Davis, M.A., \& Hutchings, C.H. (1981). Cognitive and emotional components of anxiety: Literature review and a revised worry-emotional scale. Journal of Educational Psychology, 73, 541-555.

Papadopoulou, A., Theodorakis, N.D., Tsigilis, N., \& Tsalis, G. (2006). Sex and sport-related differences in satisfaction among Greek swimmers. Psychological Reports, 98(2), 389-394.

Riemer, H., \& Chelladurai, P. (1998). Development of the Athlete Satisfaction Questionnaire (ASQ). Journal of Sport \& Exercise Psychology, 20, 127-156.

Salmon, P. (2001). Effects of physical exercise on anxiety, depression, and sensitivity to stress: A Unifying Theory. Clinical Psychology Review, 21(1), 33-61.

Stavrou, N., Zervas, G., Kakkos, V., \& Psichountaki, M. (1998). Intensity and direction of competitive anxiety. In I. Theodorakis, A. Papaioannou, \& M. Goudas (Ed.). Proceedings from: $2^{\text {nd }}$ International Conference of Sports Psychology. Greece: Trikala.

Spielberger, C. (1989). Stress and anxiety in sports. In D. Hackfort \& C. Spielberger (Eds). Anxiety in Sports: An International Perspective (pp. 3-7). New York: Hemisphere.

Woodman, T., \& Hardy, L. (2003). The relative impact of cognitive anxiety and self-confidence upon sport performance. A meta-analysis. Journal of Sport Sciences, 21, 443-457. 


\section{AUTHOR'S ADDRESS:}

\section{Evangelos Bebetsos}

School of Physical Education \& Sport Science

Democritus University of Thrace

Komotini, Greece

E-mail: empempet@phyed.duth.gr

Received: 1 April 2019; Accepted: 24 September 2019 